\title{
СОВРЕМЕННОЕ СОСТОЯНИЕ И ПРОБЛЕМЫ ИННОВАЦИОННОГО РАЗВИТИЯ СФЕРЫ МЕДИЦИНСКИХ УСЛУГ
}

\author{
(c) 2019 Борисова Анна Константиновна \\ аспирант кафедры Предпринимательства и логистики \\ Российский экономический университет имени Г.В. Плеханова, Россия, Москва \\ E-mail: ak.borisova@mail.ru
}

В статье проанализирована роль учреждений здравоохранения в общем инновационном развитии сферы медицинских услуг. Представлены результаты анонимного анкетирования специалистов в области сферы медицинских услуг, в том числе руководителей учреждений здравоохранения и руководителей структурных подразделений учреждений здравоохранения в области проблем и тенденций инновационного развития, а также проанализированы опыт и роль учреждений здравоохранения в общем инновационном развитии сферы медицинских услуг.

Ключевые слова: инновации, инновационное развитие, сфера медицинских услуг, критерии инноваций, инновационная деятельность, инновационный потенциал, организации сферы медицинских услуг, здравоохранение.

В настоящее время важнейшим условием гармоничного совершенствования сферы медицинских услуг является поступательное инновационное развитие отрасли, что обусловлено как социально-экономическими парадигмами развития общества и логическими законам хозяйствования, так и целевыми приоритетами государственных и муниципальных программ.

Сегодня как по мнению исследователей, так и согласно статистическим данным отмечается низкий уровень инновационного развития сферы медицинских услуг. По нашему мнению, именно системный подход как основополагающий фактор инновационного развития сферы медицинских услуг в виде формирования концептуальной многоуровневой модели организационно-экономических механизмов способен решить эту задачу.

«Инновационная деятельность в сфере услуг имеет к тому же тенденцию к непрерывности, представляя собой серию поэтапных изменений в продуктах и процессах. Иногда это может затруднять выявление инноваций в сфере услуг как отдельных событий, т.е. как фактов осуществления значительного изменения в продуктах, процессах или иных методах.» [4]

Необходимо отметить, что разграничение особенностей и принципов функционирования микроуровня и макроуровня отрасли здравоохранения, а также их роль в общем процессе инновационного развития сферы медицинских представляет интерес для изучения данного во- проса.

Так, по мнению исследователей именно инновационная инфраструктура является ключевым фактором осуществления эффективной инновационной деятельности как базовая составляющая инновационной экономики в виде совокупности различных учреждений здравоохранения [1,3].

При этом анализ организаций сферы услуг в качестве ключевых субъектов инновационной инфраструктуры, по нашему мнению, должен стать одним из первых этапом анализа модели инновационного развития сферы медицинских услуг. При этом организационно-экономические механизмы обеспечения инновационной деятельности сферы медицинских услуг должны обеспечивать непрерывное развитие и совершенствование инновационного потенциала учреждений здравоохранения.

В рамках настоящего исследования нами проведено анонимное анкетирование 216 респондентов, среди которых 72 врача-специалиста и 144 руководителя структурного подразделения и учреждения здравоохранения. Следует отметить, что все респонденты имеют стаж работы в здравоохранении, в том числе на руководящих должностях более 10 лет.

Текущее положение здравоохранения в РФ большинство опрошенных оценили как «неопределенное», что составляет $61 \%$ всех ответов, при этом 30\% респондентов считают, что сегодня здравоохранение РФ имеет критическое по- 
ложение, что отражено на рисунке 1.

При этом основными проблемами развития сферы услуг, по мнению респондентов, являются:

1) недостаточное финансирование;

2) неэффективное взаимодействие амбулаторных и стационарных звеньев оказания медицинской помощи;

3) медленное обновление медицинских технологий и оборудования;

4) низкий уровень мотивации врачебных кадров.

Всесторонний анализ проблем, препятствующих развитию сферы медицинских услуг, интересен в целях создания многоуровневой модели инновационного развития, поскольку, по нашему мнению, именно мероприятия по устранению вышеуказанных препятствий способствуют максимальному инновационному развитию посредством формирования устойчивой инновационной среды, в условиях которой инновации способны давать максимально возможный результат.

Следует отметить, что только $34 \%$ опрошенных верно интерпретируют термин «инновация», как любое нововведение, обеспечивающее необходимую экономическую и/или общественную выгоду, остальная доля респондентов под «инновацией в сфере медицинских услуг» понимают новую или усовершенствованную технологию оказания медицинской помощи.

На вопрос, реализуется ли в учреждении, в котором Вы работаете, внедрение и развитие инноваций, $56 \%$ респондентов ответили, что нет, $27 \%$ имеют возможность реализовать собственные идеи и $17 \%$ внедряют инновации, регламентируемые вышестоящими организациями. При этом 81\% опрошенных имеют идеи инновационного развития, но всего лишь $15 \%$ из них является предметом интереса для других сотрудников организации сферы медицинских услуг и вышестоящих организаций. Наглядно вышеуказанные данные продемонстрированы на рисунке 2.

При этом необходимо отметить, что, по словам опрошенных нами специалистов, вышестоящими организациями или любыми уполномоченными органами не проводятся мероприятия по донесению и разъяснению информации о разработке и внедрению инноваций сферы медицинских услуг.

Особо необходимо подчеркнуть мнение респондентов о том, является ли инновационно ориентированной настоящая сфера медицинских услуг в РФ. Так, однозначно, что сфера услуг не является инновационно ориентированной, ответили 23\% опрошенных, 51\% полагает, что скорее нет, чем да, и 26\% - скорее да, чем нет Вариант «да» - сфера услуг РФ является инновационной, не был отмечен никем, что отражено на рисунке 3.

$100 \%$ анкетируемых считают, что инновации необходимы и представляют абсолютную ценность всегда как для страны и общества в целом,

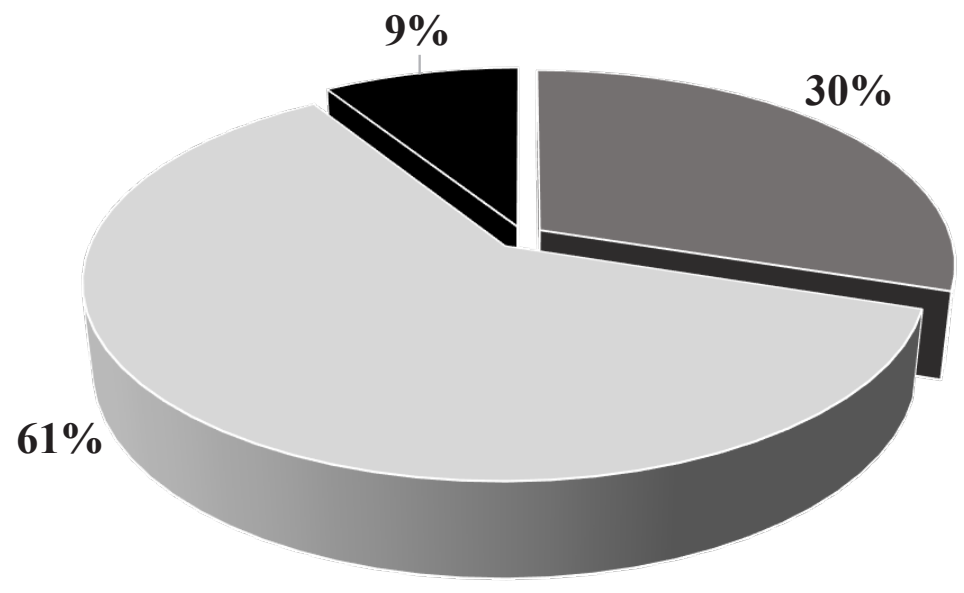

- критическое неопределенное - затрудняюсь ответить 


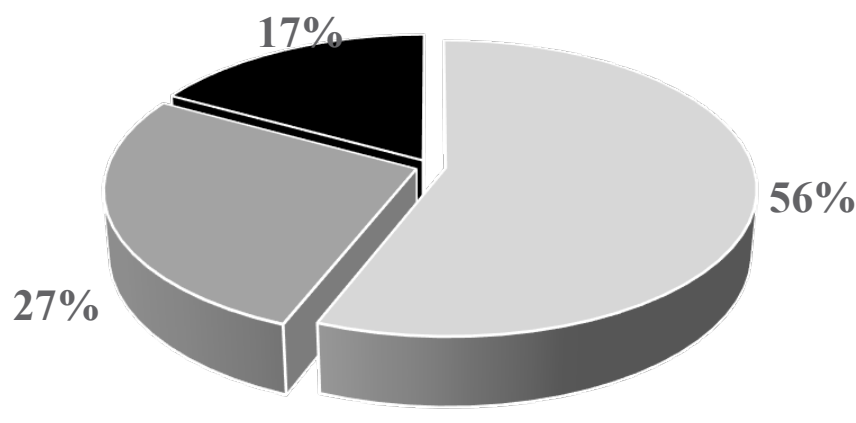

не реализуется
- имеется возможность реализовать собственные идеи

- внедряются инновации, регламентируемые вышестоящими организациями

Рис. 2. Реализация внедрения и развития инноваций в учреждениях сферы медицинских услуг

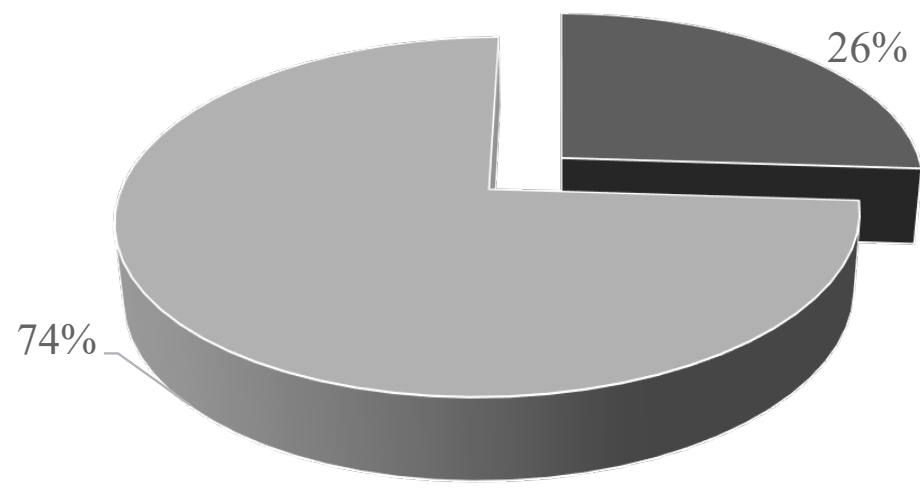

- является

- не является

Puc. 3. Мнения респондентов о том, является ли инновационно ориентированной настоящая сфера медицинских услуг в РФ

так и для сферы медицинских услуг, в частности. При этом все респонденты считают, что в настоящих социально-экономических условиях развития необходимы не радикальные, а постепенные менее дорогостоящие инновации, которые позволят постепенно, но устойчиво и планомерно наращивать шаг за шагом инновационный потенциал отрасли.

Среди проблем, которые препятствуют инновационному развитию сферы медицинских услуг в настоящее время в РФ респондентами выделены следующие:

1) низкая степень информированности сотрудников медицинских организаций,

2) несовершенство нормативно-законодательной базы,

3) нестабильность и низкий уровень социально-экономического развития РФ как отсутствие фундамента для инновационного развития,
4) отсутствие мотивации у сотрудников вышестоящих организаций,

5) отсутствие единого уполномоченного координационного центра по сбору, оценке, внедрению, развитию и контролю инновационного развития в сфере медицинских услуг,

6) неготовность общества потребления к инновациям в здравоохранении.

Таким образом, подводя итог, хочется отметить, что инновации в условиях инновационно ориентированной экономики являются необходимым условиям гармоничного развития любой отрасли, в том числе и здравоохранения. Инновационное развитие сферы медицинских услуг осуществляется исключительно в директивном порядке органами государственной власти.

На наш взгляд, только системный подход, учитывающий все элементы многокомпонентной модели инновационного развития сферы 
медицинских услуг, такие как микроуровень, а именно практические учреждения здравоохранения и обратная связь с ними. Поскольку именно в процессе оказания медицинских услуг выявляются реальные практические проблемы и идеи усовершенствования системы, которые при научно ориентированном подходе и правильном управлении возможно станут инновациями, способными существенно повлиять на действующую систему. «При постоянном совершенствовании инновационного потенциала учреждения здравоохранения могут обеспечить дальнейшее развитие и сохранить конкурентоспособность.» [2]

При этом, следует отметить, что на практике неправомерно вышеуказанному аспекту не уделяется должное внимание. Полагаем, что идеи инновационного развития здравоохранения сотрудников, в том числе руководителей, организаций сферы медицинских услуг должны быть собраны и проанализированы уполномоченными органами как часть многокомпонентной модели инновационного развития сферы медицинских услуг.

\section{Библиографический список}

1. Комов М.С. Роль инноваций в антикризисном управлении // Молодой ученый.- 2016.- № 19.- С. 458459. - URL: https//moluch.ru/archive/123/33978/

2. Пшеничников И.В., Полина О.С. Совершенствование инновационного потенциала медицинских учреждений// Молодой ученый._-2016. - № 11.-C. 928-930. URL: https://moluch.ru/arhive/115/30910/

3. Трибушная В.X. Инновационная инфраструктура как необходимость поддержки предпринимательства: технопарки и стратегическое управление: Монография, Ижевск: Изд-во «Удмуртский университет», 2011.240 c.

4. Руководство Осло. Рекомендации по сбору и анализу данных по инновациям URL: https://mgimo.ru/upload/ docs_6/ruk.oslo.pdf 